\title{
Redox Control of meso-Zinc(II) Ferrocenylporphyrin Based Fluorescence Switches
}

\author{
Jonathan Rochford, ${ }^{\dagger, \ddagger}$ A. Denise Rooney, ${ }^{\S}$ and Mary T. Pryce ${ }^{\star, \dagger}$ \\ Received February 21, 2007 \\ The efficient on/off switching of fluorescence from thienyl- and \\ phenyl-substituted porphyrin-ferrocene dyads is achieved through \\ redox control of excited-state electron-transfer quenching.
}

School of Chemical Sciences, Dublin City University, Dublin 9, Ireland, and Department of Chemistry, National University of Ireland Maynooth, Co. Kildare, Ireland

Their strong absorption and fluorescence properties together with their synthetic versatility have resulted in the widespread application of porphyrins in systems ranging from simple monomers to large dendritic and multicomponent structures, in areas as diverse as artificial photosynthesis and light-harvesting arrays ${ }^{1}$ to the construction of extended $\pi$ systems for organic semiconductors, ${ }^{2}$ liquid crystals, ${ }^{3}$ optical limiters, ${ }^{4}$ photovoltaic devices, ${ }^{5}$ light-emitting diodes, ${ }^{6}$ nonlinear optical materials, ${ }^{6}$ and numerous biological applications. ${ }^{7}$ Controlling the photonic output of porphyrins postsynthetically remains, however, a significant challenge. Redox modulation of fluorescence through a covalently bound switch is of special relevance toward practical application in electro-optic devices. ${ }^{8}$

Here we report a relatively simple approach to achieving on/off switching of porphyrin fluorescence through the use of the ferrocene/ferrocenium $\left(\mathrm{Fc} / \mathrm{Fc}^{+}\right)$redox couple. This approach makes use of the quenching of the porphyrin fluorescence by excited-state electron transfer from the

* To whom correspondence should be addressed. E-mail: mary. pryce@dcu.ie. Tel.:+353 17008005.

† Dublin City University.

¥ Present address: Chemistry Department, Rutgers University, 73 Warren Street, Newark, NJ 07102.

$\S$ National University of Ireland Maynooth.

(1) The Porphyrin Handbook, Kadish, K. M., Smith, K. M., Guilard, R., Eds.; Academic Press: Boston, MA, 2003; Vol. 18.

(2) Aratani, N.; Osuka, A.; Cho, H. S.; Kim, D. J. Photochem. Photobiol. C: Photochem. Rev. 2002, 3, 25.

(3) Nakai, T.; Ban, K.; Ohta, K.; Kimura, M. J. Mater. Chem. 2002, 12, 844.

(4) Calvete, M.; Ying Yang, G.; Hanack, M. Synth. Met. 2003, 141, 231.

(5) Krebs, F. C.; Hagemann, O.; Jorgensen, M. Sol. Energy Mater. Sol. Cells 2004, 83, 211.

(6) Che, C.-M.; Hou, Y.-J.; Chan, M. C. W.; Guo, J.; Liu, Y.; Wang, Y. J. Mater. Chem. 2003, 13, 1362 .

(7) (a) Lang, K.; Mosinge, J.; Wagnerová, D. M. Coord. Chem. Rev. 2004 248, 321. (b) McMillin, D. R.; Shelton, A. H.; Bejune, S. A.; Fanwick, P. E.; Wall, R. K. Coord. Chem. Rev. 2005, 249, 1451. (c) Barth, R. F.; Coderre, J. A.; Vicente, M. G. H.; Blue, T. E. Clin. Cancer Res. 2006, 6, 145.

10.1021/ic0703326 CCC: $\$ 37.00$ C 2007 American Chemical Society Published on Web 08/08/2007

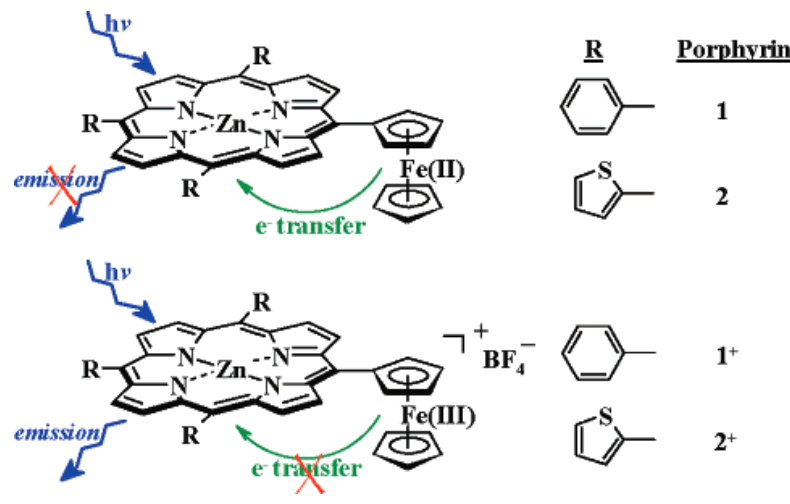

Figure 1.

ferrocene to the porphyrin, ${ }^{9,10}$ a process that, in the present systems, can be "switched on", reversibly, by oxidation to the ferrocenium ion. The triphenyl- and trithienylzinc(II) porphyrin-ferrocene dyads (1 and 2, respectively; Figure

(8) (a) Bergonzi, R.; Fabbrizzi, R.; Licchelli, M.; Mangano, C. Coord. Chem. Rev. 1998, 170, 31. (b) Fabbrizzi, R.; Licchelli, M.; Palaviccini, P. Acc. Chem. Res. 1999, 32, 846. (c) Li, H.; Jeppesen, J. O.; Levillain, E.; Becher, J. Chem. Commun. 2003, 846. (d) Zhang, G.; Zhang, D.; Guo, X.; Zhu, D. Org. Lett. 2004, 6, 1209. (e) Guo, X.; Zhang, D.; Tao, H.; Zhu, D. Org. Lett. 2004, 6, 2491. (f) Xiao, X.; Xu, W.; Zhang, D.; Xu, H.; Lu, H.; Zu, D. J. Mater. Chem. 2005, 15, 2557. (g) Xiao, X.; Xu, W.; Zhang, D.; Xu, H.; Liu, L.; Zu, D. New J. Chem. 2005, 29, 1291. (h) Yan, P.; Holman, M. W.; Robustelli, P.; Chowdhury, A.; Ishak, F. I.; Adams, D. M. J. Phys. Chem. B 2005, 109, 130. (i) Martínez, R.; Retara, I.; Tárrage, A.; Molina P.; Veciana J. Chem. Commun. 2006, 3809.

(9) (a) Wollman, R. G.; Hendrickson, D. N. Inorg. Chem. 1977, 16, 3079. (b) Schmidt, E. S.; Calderwood, T. S.; Bruice, T. C. Inorg. Chem. 1986, 25, 3718. (c) Burrell, A. K.; Cambell, W. M.; Officer, D. L. Tetrahedron Lett. 1997, 38, 1249. (d) Boyd, P. D. W.; Burrell, A. K.; Campbell, W. M.; Cocks, P. A.; Gordon, K. C.; Jameson, G. B.; Officer, D. L.; Zhao, Z. Chem. Commun. 1999, 637. (e) Burrell, A. K.; Cambell, W. M.; Officer, D. L.; Scott, S. M.; Gordon, K. C.; McDonald, M. R. J. Chem. Soc., Dalton Trans. 1999, 3349. (f) Cheng, K. L.; Li, H.-W.; Ng, D. K. P. J. Organomet. Chem. 2004, 689, 1593. (g) Imahori, H.; Kimura, M.; Hosomizu, K.; Sato, T.; Ahn, T. K.; Kim, S. K.; Kim, D.; Nishimura, Y.; Yamazaki, I.; Araki, Y.; Ito, O.; Fukuzumi, S. Chem.-Eur. J. 2004, 10, 5111. (h) D’Souza, F.; Smith, P. M.; Gadde, S.; McCarty, A. L.; Kullman, M. J.; Zandler, M. E.; Itou, M.; Araki, Y.; Ito, O. J. Phys. Chem. B 2004, 108, 11333. (i) Tanihara, J.; Ogawa, K.; Kobuke, Y. J. Photochem. Photobiol. A: Chem. 2006, 178, 140. (j) Nakagawa, H.; Ogawa, K.; Satake, A.; Kobuke, Y. Chem. Commun. 2006, 1560. (k) Li, Y.; Gan, Z.; Wang, N.; He, X.; Li, Y.; Wang, S.; Liu, H.; Araki, Y.; Ito, O.; Zhua, D. Tetrahedron 2006, 62, 4285.

Inorganic Chemistry, Vol. 46, No. 18, 20077247 


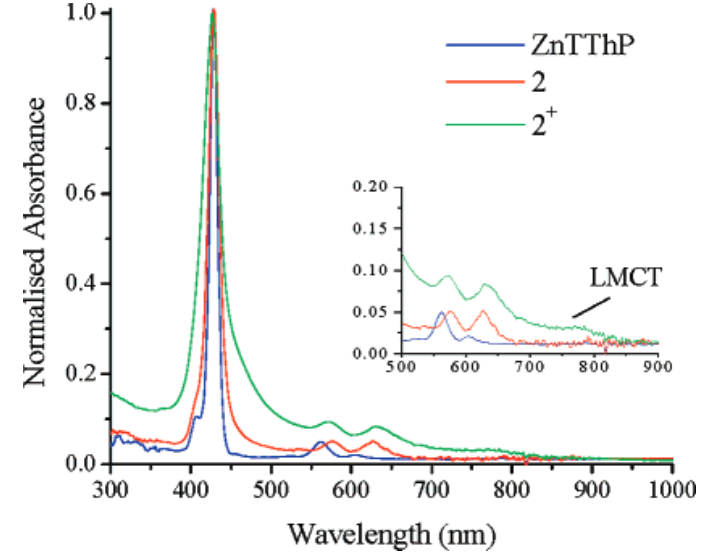

Figure 2. UV-vis-NIR spectra of ZnTThP (blue), 2 (red), and $\mathbf{2}^{+}$(green) in ethanol.

Scheme 1. Schematic of the Electron-Transfer Quenching Process Where $\mathrm{ZnPFC}^{\mathrm{II}}$ Is $\mathbf{1}$ or $\mathbf{2}$ and $\mathrm{ZnPFC}{ }^{\mathrm{III}}$ Is $\mathbf{1}^{+}$or $\mathbf{2}^{+}$

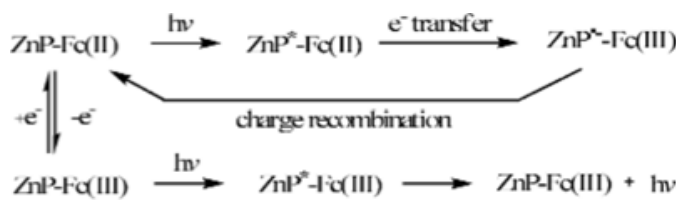

1) were prepared by standard procedures (see the Supporting Information for details). The absorption spectra of both $\mathbf{1}$ and 2 show the characteristic Soret and $Q$ absorption bands of the porphyrin chromophore (Figure 2).

The full width at half-maximum (fwhm) values of the Soret bands show an increase in comparison to the tetraaryl analogues, indicating some vibronic coupling between the $\pi$ system of the porphyrin $S_{2}$ electronic state and the mesoferrocenyl substituent (Table 1) ${ }^{11}$ More substantial red shifts are seen for the $Q$ bands of $\mathbf{1}$ and $\mathbf{2}$, suggesting a stronger interaction of the meso-ferrocenyl substituent with the $\mathrm{S}_{1}$ electronic state of the porphyrin than with the $S_{2}$ (Table 1 ).

The relative intensity of the $Q(0,0)$ band increases considerably with respect to the adjacent $Q(1,0)$ absorption band for both ferrocenylporphyrins, consistent with a decrease in the HOMO-LUMO energy gap (Table 2). In contrast to the tetraaryl analogues zinc(II) tetraphenylporphyrin (ZnTPP) and zinc(II) tetrathienylporphyrin (ZnTThP), the porphyrin ${ }^{1} \pi-\pi^{*}$ fluorescence of both $\mathbf{1}$ and $\mathbf{2}$ is almost completely quenched and no evidence for a ${ }^{3} \pi-\pi^{*}$ excited state was obtained by transient absorption spectroscopy (vide infra).

The presence of ferrocene at the meso position quenches the ${ }^{1} \pi-\pi^{*}$ and ${ }^{3} \pi-\pi^{*}$ excited states of the porphyrin ring through a rapid electron-transfer mechanism, which significantly reduces the emission quantum yields. ${ }^{12}$ Previous studies have reported electron-transfer quenching in covalently linked porphyrin-ferrocene dyads, but to the best of our knowledge, the only report in the literature with comparable levels of quenching is for a free base tetraferrocenylporphyrin. ${ }^{13}$

(10) Beer, P. D.; Kurek, S. S. J. Organomet. Chem. 1989, C6-C8, 366

(11) Lin, V. S.; DiMagno, S. G.; Therien, M. J. Science 1994, 264, 1105.

(12) Thorton, N. B.; Wojtowicz, H.; Netzel, T.; Dixon, D. W. J. Phys. Chem. B 1998, 102, 2101

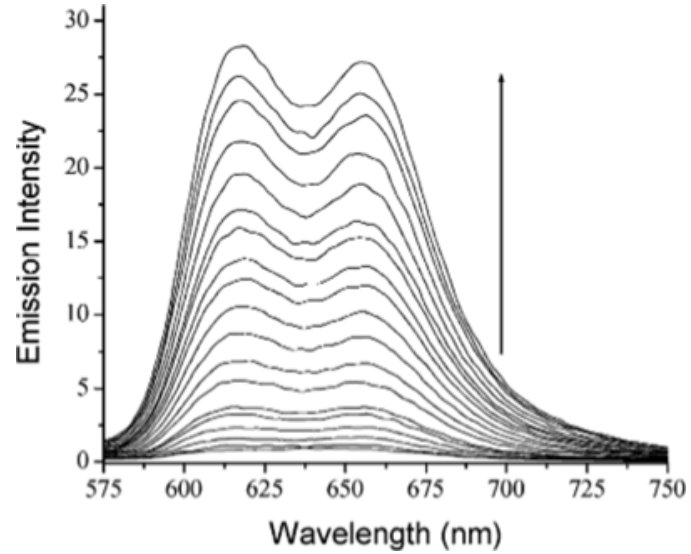

Figure 3. Increase in the fluorescence intensity observed upon one-electron oxidation of 1 in dichloromethane $\left(0.1 \mathrm{M} \mathrm{Bu}_{4} \mathrm{NBF}_{4}\right)$.

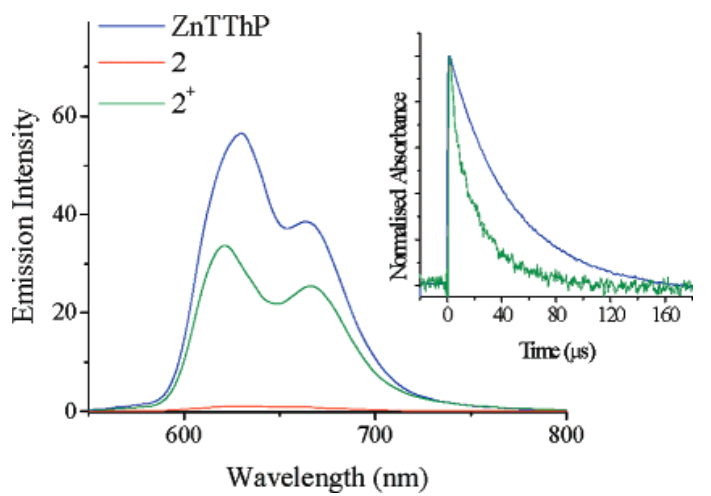

Figure 4. Fluorescence spectra for ZnTThP, 2, and $2^{+}$(in ethanol). Inset: Normalized transient absorption decay traces of ZnTThP $\left({ }^{3} \tau=40 \mu \mathrm{s}\right)$ and $2^{+}\left({ }^{3} \tau=20 \mu \mathrm{s}\right)$ at $490 \mathrm{~nm}\left(\lambda_{\text {exc }}=532 \mathrm{~nm} ; 1\right.$ atm of argon $)$.

The first and second oxidations to the porphyrin monoradical cation $\left(\mathrm{P}^{\bullet+}\right)$ and diradical cation $\left(\mathrm{P}^{+}\right)$and reductions to the porphyrin monoradical anion $\left(\mathrm{P}^{{ }^{-}}\right)$and anion $\left(\mathrm{P}^{-}\right)$for $\mathbf{1}$ and $\mathbf{2}$ are similar to those observed for ZnTPP and ZnTThP, respectively (Table 2). ${ }^{14}$ In addition, one-electron $\mathrm{Fc} / \mathrm{FC}^{+}$ redox couples are present for $\mathbf{1}$ and 2 .

The Fc/Fc ${ }^{+}$redox couples for $\mathbf{1}$ and $\mathbf{2}$ occur at 20 and 40 $\mathrm{mV}$, respectively, positive of unsubstituted ferrocene, indicating the greater delocalization of dyad $\mathbf{2}$ compared to $\mathbf{1}$. For 1, the potential of the first oxidation of the porphyrin is shifted $110 \mathrm{mV}$ anodically compared to ZnTPP, possibly reflecting the more delocalized nature of the redox processes over the thienyl substituents of $\mathbf{2}$ than the phenyl substituents of 1.

The oxidation of the ferrocene units of $\mathbf{1}$ and $\mathbf{2}$ was monitored by UV-vis-NIR and emission spectroscopy. One-electron oxidation of the ferrocene moiety in porphyrinferrocene dyads $\mathbf{1}$ and $\mathbf{2}$ resulted in the appearance of a lowenergy ferrocenium ligand-to-metal charge-transfer (LMCT) absorption $\left(\mathbf{1}^{+}, \lambda_{\max }=789 \mathrm{~nm} ; \mathbf{2}^{+}, \lambda_{\max }=767 \mathrm{~nm}\right) .{ }^{15,16}$ The delocalization of the LMCT band to include the porphyrin unit itself is reflected in the increase in the fwhm of the Soret

(13) Nadtochenko, V. A.; Denisov, N. N.; Gak, V. Yu.; Abramova, N. V.; Loim, N. M. Russ. Chem. Bull. 1999, 48, 1900.

(14) Bhyrappa, P.; Bhavana, P. Chem. Phys. Lett. 2001, 349, 399.

(15) Sohn, Y. S.; Hendrickson, D. N.; Gray, H. B. J. Am. Chem. Soc. 1971, 93, 3603.

7248 Inorganic Chemistry, Vol. 46, No. 18, 2007 
COMMUNICATION

Table 1. UV-vis-NIR, Transient Absorption, and Fluorescence Data ${ }^{a}$

\begin{tabular}{|c|c|c|c|c|c|c|c|}
\hline porphyrin & Soret (nm) & fwhm $\left(\mathrm{cm}^{-1}\right)$ & $Q$ bands (nm) & CT (nm) & fluor. $\lambda_{\max } / \mathrm{nm}\left({ }^{\circ}\right)$ & ${ }^{1} \tau(\mathrm{ns})^{b}$ & ${ }^{3} \tau(\mu \mathrm{s})$ \\
\hline ZnTPP & $421(25.26)$ & 508 & 556 (1.00), 595 (0.38) & & $606,656(0.043)$ & 1.96 & 22 \\
\hline ZnTThP & 428 (21.52) & 655 & 562 (1.00), 604 (0.27) & & 630, $664(0.014)$ & $0.56 / 1.32$ & 40 \\
\hline 1 & $424(28.06)$ & 835 & 572 (1.00), 620 (1.12) & & $c$ & & \\
\hline 2 & $429(24.64)$ & 924 & $577(1.00), 626(0.96)$ & - & $632,656\left(2.52 \square 10^{-4}\right)$ & & \\
\hline $\mathbf{1}^{+}$ & $423(13.96)$ & 1062 & $539(1.00)$ & $789(0.22)$ & $610,660(0.006)$ & $0.51 / 0.94^{d, e}$ & 12 \\
\hline $2^{+}$ & $426(10.73)$ & 1544 & 573 (1.00), 631 (0.86) & $767(0.25)$ & $622,666(0.010)$ & $0.31 / 1.92^{d, e}$ & 20 \\
\hline
\end{tabular}

${ }^{a}$ All data were obtained in an ethanol solution. Included in parentheses are the peak intensities relative to the $Q(1,0)$ band. ${ }^{b}$ Obtained by time-correlated single-photon counting. ${ }^{c}$ No fluorescence was observed in our experiments. ${ }^{d}$ Carried out following in situ oxidation with ceric(IV) ammonium nitrate. ${ }^{e}$ Biexponential decay kinetics were observed for porphyrins ZnTThP, $\mathbf{1}^{+}$, and $\mathbf{2}^{+}(22: 78 \%, 70: 30 \%$, and 4:96\% of the shorter:longer lifetimes, respectively; the origin of the biexponential component has not yet been assigned).

Table 2. Electrochemical Data Reported vs Fc/Fc ${ }^{+}$

\begin{tabular}{lcccccc}
\hline \multirow{2}{*}{ porphyrin } & \multicolumn{3}{c}{$E_{\text {ox }}(\mathrm{V})$} & & \multicolumn{2}{c}{$E_{\text {red }}(V)$} \\
\cline { 2 - 4 } \cline { 6 - 7 } $\mathrm{Fe}^{\mathrm{II}} / \mathrm{Fe}^{\mathrm{III}}$ & $\mathrm{P} / \mathrm{P}^{\bullet+}$ & $\mathrm{P}^{\bullet}+\mathrm{P}^{+}$ & & $\mathrm{P} / \mathrm{P}^{\bullet-}$ & $\mathrm{P}^{\bullet}-\mathrm{P}^{-}$ \\
\hline ZnTPP & & 0.34 & 0.66 & & -1.85 & -2.21 \\
ZnTThP & & 0.43 & 0.62 & & -1.71 & -2.05 \\
$\mathbf{1}$ & 0.02 & 0.45 & 0.70 & & -1.93 & -2.30 \\
$\mathbf{2}$ & 0.04 & 0.47 & 0.68 & & -1.75 & -2.11
\end{tabular}

absorption (Table 1). Gradual formation of the corresponding ferrocenium cations in situ is evident in the UV-vis-NIR spectra (see the Supporting Information). Oxidation of the ferrocene unit eliminates the possibility of electron-transfer quenching of the porphyrin excited state. Following oxidation of $\mathrm{Fe}^{\mathrm{II}}$ to $\mathrm{Fe}^{\mathrm{III}}$, the characteristic porphyrin emission is restored through preclusion of the electron-transfer process (Scheme 1 and Figure 3).

The relative fluorescence quantum yields for $\mathbf{1}^{+}$and $\mathbf{2}^{+}$ are $14 \%$ and $71 \%$ in comparison to ZnTPP and ZnTThP, respectively. Incomplete recovery of the fluorescence quantum yield for both $\mathbf{1}^{+}$and $\mathbf{2}^{+}$is attributed to quenching processes, including intersystem crossing of the porphyrin ${ }^{1} \pi-\pi^{*}$ excited state to the new LMCT state and energytransfer quenching by the ferrocenium unit. Upon oxidation of the ferrocene unit, the lowest singlet LMCT excited state associated with ferrocenium has energies of 1.57 and 1.61 $\mathrm{eV}$ for $\mathbf{1}^{+}$and $\mathbf{2}^{+}$, respectively. Energy transfer is now a feasible means of quenching.

(16) Malaun, M.; Kowallick, R.; McDonagh, A. M.; Marcaccio, M.; Paul, R. L.; Asselberghs, I.; Clays, K.; Persoons, A.; Bildstein, B.; Fiorini, C.; Nunzi, J.-M.; Ward, M. D.; McCleverty, J. A. J. Chem. Soc., Dalton Trans. 2001, 3025.

(17) Gupta, I.; Ravikanth, M. J. Photochem. Photobiol. A: Chem. 2006, 177,156
The more pronounced recovery of fluorescence for $\mathbf{2}^{+}$may be due to delocalization of the porphyrin excited-state electron density onto the peripheral thien-2-yl rings, thus reducing the energy-transfer efficiency to the ferrocenium moiety..$^{17}$

Transient absorption spectroscopy was employed to probe the ${ }^{3} \pi-\pi^{*}$ excited states of $\mathbf{1}^{+}$and $2^{+}$. Both of the porphyrin-ferrocenium dyads show transient absorption signals indicative of the $\pi-\pi^{*}$ triplet excited-state decay (Figure 4). As for the reduced quantum yield of fluorescence

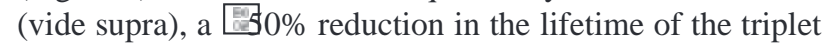
state in comparison to ZnTPP and ZnTThP, respectively, is observed (Table 1). Further studies are required to confirm the mechanism of triplet-state quenching. Shorter singlet excited-state lifetimes were similarly observed for $\mathbf{1}^{+}$and $2^{+}$(Table 1).

In conclusion, in the present Communication we have demonstrated that complete or near-complete electrontransfer quenching of porphyrin fluorescence can be achieved by direct attachment of a ferrocene unit to the meso position of the zinc(II) porphyrin. Oxidation of the ferrocene moiety to the ferrocenium state results in a recovery of fluorescence at the porphyrin center. The switching on and off of the electron-transfer quenching pathway allows for efficient redox control of porphyrin luminescence.

Acknowledgment. The authors thank Enterprise Ireland for financial support. Dr. Wesley Browne is thanked for helpful discussions.

Supporting Information Available: Synthesis, spectroelectrochemistry, and transient absorption spectroscopy. This material is available free of charge via the Internet at http://pubs.acs.org.

IC0703326 